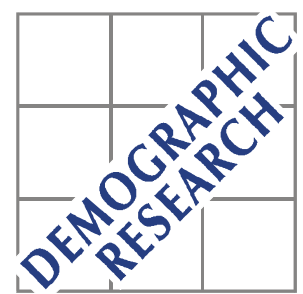

Demographic Research a free, expedited, online journal of peer-reviewed research and commentary in the population sciences published by the Max Planck Institute for Demographic Research Doberaner Strasse $114 \cdot$ D-18057 Rostock · GERMANY www.demographic-research.org

DEMOGRAPHIC RESEARCH

VOLUME 3, ARTICLE 9

PUBLISHED 1 NOVEMBER 2000

www.demographic-research.org/Volumes/Vol3/9/

DOI: $10.4054 /$ DemRes.2000.3.9

\title{
Change in the Prevalence of Diseases among Older Americans: 1984-1994
}

\section{Eileen M. Crimmins}

Yasuhiko Saito

(C) 2000 Max-Planck-Gesellschaft. 


\title{
Change in the Prevalence of Diseases among Older Americans: 1984-1994
}

\author{
Eileen M. Crimmins ${ }^{1}$ \\ Yasuhiko Saito $^{2}$
}

\begin{abstract}
Paper presented at the Annual Meetings of the Population Association of America, 1998, Chicago, Illinois.
\end{abstract}

\begin{abstract}
The reported prevalence of diseases increased among older Americans in recent years. The largest increases have been in the proportion of the population with heart disease and cancer. There has also been a decrease in the number of older persons with no disease and an increase in the proportion of people with multiple conditions. The severity of disability among women with most diseases has been reduced; among men there has been no reduction in disability. Both the prevalence of diseases and the prevalence of disability are indicators of population health that result from a complicated process of disease and disability onset, survival probability and death rates for people with and without these health conditions. While change in disease prevalence and disability has been based on analysis of two surveys representative of the U.S. noninstitutionalized population taken ten years apart and designed to monitor health change, it is possible that changes in medical knowledge or service usage could play a role in increased reporting of disease presence.
\end{abstract}

\footnotetext{
${ }^{1}$ University of Southern California; email: crimmin@rcf.usc.edu

${ }^{2}$ Nihon University; email: yasuhik@cin.nihon-u.ac.jp
} 


\section{Introduction}

There has been considerable research on trends in health of the older American population focused on trends in disability [Crimmins, Saito, and Reynolds 1997, Manton, Stallard, and Corder 1997]. Disability is an important dimension of health but clarification of trends in the other health dimensions is important for understanding overall trends in health. In recent conceptualizations of the dimensions of health, the onset of diseases and conditions are seen as the initial health changes underlying functioning loss and disability [Verbrugge and Jette 1994]. For this reason, change over time in the prevalence of disease is important in monitoring trends in the health of the older population.

Change in the prevalence of diseases is an important indicator of the combined effects of past levels of, and changes in, mortality and disease incidence on subsequent population health. Empirical evidence on trends in disease provides an additional indicator of whether current mortality and incidence trends are leading to a compression or expansion of morbidity. Linking functioning loss and disability to disease can provide evidence of whether the severity of diseases as well as the presence of diseases has changed over time. Finally, the cost of health care is highly related to the number of persons who must be treated or monitored for various diseases; so the number of people with diseases provides a valuable indicator of the potential demand for health care.

This paper will address the following questions: How has the prevalence of major diseases and conditions changed in the older population of the United States between 1984 and 1994? How has the severity of disability and functioning loss among those with diseases changed over the period? How has comorbidity or the prevalence of multiple conditions changed in this period?

\section{Background}

\subsection{Prevalence as an indicator of population health}

The prevalence of diseases in the population is an indicator of the current stock of health. It is the result of past rates of disease incidence, disease progression, and survival. Over time, the prevalence of disease may change because of increases or decreases in risk factors for various diseases and because of increasing ability to treat diseases in order to delay their progression to disability and death. The relative size of the change in incidence rates and survival rates will determine change in disease prevalence. Simulation analysis relating population disability levels to change in incidence of disability and mortality has clarified the primary role of incidence change in affecting population health as well as the potential negative role of increasing survival without changing incidence [Crimmins, Hayward, and Saito 1994]. 
The major diseases and conditions of old age can be divided into fatal and non-fatal conditions. For the lethal diseases of old age, the potential end point of an incident case may be death. Many of the causes of disability in old age, however, are not lethal and one survives with them until death from some other cause. Therefore, the prevalence of non-mortal disease is determined by the incidence of those conditions, the length of life after incidence, and the death rate from lethal conditions. Trends in the prevalence of fatal and non-fatal condition may differ.

Trends in disease presence do not necessarily represent trends in disease of a specified severity. Even with a constant prevalence of disease over time, the severity of diseases could change. It is possible that in more recent years, people are learning of the presence of less severe disease at an earlier stage because of the growing ability to diagnose noninvasively. Prevalence of disease could also increase because of increased use of medical services.

\subsection{Empirical Evidence of Changes in Disease Prevalence}

There have been a number of studies of trends in the prevalence of diseases and conditions among the elderly population. Manton and associates, using the U.S. National Long-Term Care Survey for the 1982 to 1989 period, examined changes in the prevalence of 16 diseases and conditions [Manton, Stallard, and Corder 1995]. After controlling for age, sex, and disability status, they found reductions in the prevalence of arthritis, arteriosclerosis, hypertension, stroke, other circulatory diseases, emphysema and dementia. They found increases in the percent of people with Parkinson's, heart disease other than heart attack, bronchitis, pneumonia, and broken hip. In this study there was no change in the prevalence of diabetes, heart attack, cancer, and asthma. Crimmins and associates [Crimmins, Reynolds, and Saito 1999] found that during the 1980s, there were decreases in cerebro and cardiovascular diseases and arthritis among persons in their 60s. Robine and his associates found increases in the prevalence of almost all diseases between 1981 and 1991 among the old in France [Robine, Mormiche, Sermet 1998]. They found large increases in the prevalence of the most important disabling diseases - cardiovascular conditions and arthritis. In France prevalence change differed for older and younger age groups; for a number of diseases where there were prevalence increases among the old, no increases were found for younger age groups.

Other researchers have concentrated on trends in specific diseases. The reported prevalence of heart disease in the U.S. has increased by about 50\% between 1972 and 1989 [Feinleib 1995]. Several countries have reported increases in the prevalence of diabetes [Bloomgarden 1994]. Hann and associates found an increase in the prevalence of stroke and angina examining two cohorts from a large HMO in the U.S. from the beginning of the 1970s and 1980s [Hann et al 1996]. Stroke prevalence also increased in Minnesota during this period [Brown et al 1996, Shahar et al 1997].

Some of these studies have investigated change in both the prevalence of diseases and the processes by which the prevalence changes have come about. Generally, they attribute increases in 
prevalence to lengthening survival after disease diagnosis with varying pattern of change in incidence [Brown et al 1996, Feinleib 1995, Hann et al 1996, Liebson 1997, Shahar et al 1997]. Other researchers have modeled trends in incidence, mortality, and prevalence of specific diseases to see the implications for disease prevalence of assumed changes in incidence and mortality. Bonneux and associates [Bonneux et al 1994] predict that the falling mortality rates from heart disease should result in a rising prevalence of persons with heart disease. Their model, in fact, predicts that even with steady decreases in incidence of heart disease at younger old ages, in the older old ages the trend is likely to be toward both increasing incidence and prevalence among the older old.

Thus the literature is somewhat mixed in the picture that is provided of disease trends in the older population. Although the bulk of the empirical evidence is that disease prevalence is increasing, there is some indication that trends for the old may differ from those for the total population. The theoretical evidence makes it clear that if mortality from diseases is declining, there may be an effect on prevalence. If there are no accompanying declines in disease incidence but only increases in survival, prevalence of disease should increase. If both incidence and case fatality rates are declining, the effect on prevalence depends on the relative change [Crimmins, Hayward, and Saito 1994].

\section{Data and Methods}

\subsection{The 1984 and 1994 Surveys of the Aging Population (SOA)}

Data used come from the 1994-95 and 1984 Supplements on Aging to the National Health Interview Surveys (SOAI and SOAII). These surveys were designed to provide information on the health of the community dwelling population of the United States 70 years of age and over at two dates - 1984 and 1994 [Note 1]. Both surveys were designed and completed by researchers at the National Centers for Health Statistics with support from the National Institute on Aging. In 1984, 7541 persons 70 years of age and over were included in SOAI and the number for SOAII was 8767. Because of the complex sample design used to select respondents, the data are weighted to reflect the U.S. noninstitutionalized population 70 years of age and over.

In both surveys people were asked about the presence of diseases in an almost identical manner. Questions used to elicit this information are shown in Table 1. We examine trends in three sets of diseases or conditions: mortal diseases, morbid conditions and impairments. Mortal conditions, which are major causes of death among people this age, include heart disease, stroke, cancer, and diabetes. Hypertension is also included in this category as it can be considered both a disease and a risk factor for other diseases. Morbid conditions include arthritis, osteoporosis, broken hip, and glaucoma. Most of the impairments represent sensory impairments: cataracts, blindness, 
deafness, and other hearing trouble. We also include the symptom dizziness, which could be the result of a large number of underlying conditions. While the surveys were designed to be compatible, for some questions the wording was changed at the second survey. The most important change is in the question about heart disease, for which the four subquestions asked in 1984 were combined into a single question in 1994.

In order to examine severity of conditions, we look at the functioning loss and disability level among persons with each condition. Disability and functioning in the survey is measured by a series of questions on ability to perform activities of daily living (ADLs), instrumental activities of daily living (IADLs), and a set of functions called Nagi functions. Inability to perform personal care is indicated by inability to perform the seven ADL tasks including bathing, dressing, toiletting, eating, getting in and out of bed or chair, walking, and getting outside. Inability in performing the five IADL tasks (including preparing meals, managing money, using the telephone, heavy housework, and light housework) indicates additional inability in the area of self-maintenance. Finally we look at inability to perform a series of nine Nagi functions which represent physical functioning deficits that should precede ADL and IADL disability. These functions include walking a quarter of a mile, walking up ten stairs, standing for 2 hours, sitting for two hours, stooping, crouching or kneeling, reaching up over head, reaching out as if to shake someone's hand, using your fingers to grasp, lifting or carrying something as heavy as ten pounds.

\subsection{Methods}

In order to examine the significance of change over time in each disease, we pool data from the two surveys and look at the effect on disease presence of being in the later year in a series of sex-specific logistic regression equations including only two covariates: a continuous measure indicating year of age and year of survey indicated by a dummy variable. This use of the regression technique allows us to summarize the effect of time change across all ages. The models presented do not include age/year of survey interactions which would indicate age differences in time change; however, these models have been tested and results indicate that most results are consistent across ages from 70 through 90, therefore models without interactions have been presented. When the coefficient indicating change over time is statistically significant, we use the results of these equations to estimate the prevalence of diseases at age 70 for 1984 and 1994 to indicate the change over time. We use OLS regression to estimate disability and functioning problems among those with specified diseases. Again we estimate sex-specific regressions including age and survey year as the covariates. We also use OLS regression to determine change between 1984 and 1994 in comorbidity or the average number of diseases after controlling for age. Finally we use results of logistic regressions including age and year of survey to estimate the probability of having no disease or three or more diseases by type for each of the two dates. 


\section{Results}

\subsection{Change in Disease Prevalence}

There are statistically significant increases between 1984 and 1994 in the reported prevalence of most diseases among the American population 70 years of age and over. Odds ratios indicating the relative likelihood of having a condition in 1994 and 1984 after age is controlled are shown in Figures 1 (mortal conditions) and 2 (non-mortal conditions). The odds ratios are shown only where there is significant or measurable change over time; ratios for males are on the left and females are on the right. For almost all diseases the ratios are above 1 indicating a significantly higher level in 1994. There is only one significant decline - the prevalence of hypertension for females. Among females, there is no change in the prevalence of stroke survivors. For the other mortal diseases and for hypertension among males, increases in prevalence are observed. Odds ratios range from 1.12 for hypertension in males to 2.0 for cancer meaning that the relative likelihood of having a disease increased between 1984 and 1994 from 12 percent to 100 percent. For both men and women the increase in the relative likelihood of having had cancer was the greatest. The increase in the relative likelihood of reporting heart disease was the next largest.

The equations which generated the odds ratios can also be used to predict the absolute probability of having each disease at the two dates. The predicted probability of having each disease at age 70 is shown in Table 2. The two major causes of death in this age range are heart disease and cancer. The estimated reported prevalence of heart disease at age 70 has increased by 6 percentage points for men and 4 percentage points for women. The increase in reported cancer survivors is 9 percentage points for men and 5 percentage points for women.

Figure 2 shows the increase for the non-fatal conditions and impairments. For both sexes there are statistically significant increases in the prevalence of arthritis, osteoporosis, cataracts and glaucoma. There are significant increases in blindness among women. Some of the non-fatal conditions do not appear on the figure because there is no significant change in prevalence. There is no change in the prevalence of having a broken hip, hearing trouble or dizziness among either sex.

The highest odds ratios are for osteoporosis indicating that this condition has the greatest relative increase over time for both men and women. It is possible that the increase in osteoporosis prevalence represents, at least in part, the dissemination of the use of this diagnosis to describe the condition. For most of the diseases the odds ratios for men are slightly higher than those for women, indicating more relative increase over time among men. The exceptions are for the eye conditions of glaucoma and blindness where women have more relative increase than men.

The estimated probability of having arthritis at age 70 increases from .44 to .49 for men and from .59 to .62 for women at age 70 . The probability of having cataracts at age 70 has increased by .03 for both sexes. Even though the odds ratio indicated that the size of the increase in the relative 
likelihood of having osteoporosis was similar for men and women, the absolute increase ( $7 \%$ at age 70 for women) is much greater among women.

\subsection{Change in Functioning and Disability among those with Diseases}

In order to indicate change in the severity of diseases and conditions among those who have each disease, we examine change between 1984 and 1994 in the levels of disability and functioning loss among those who have each specific disease or condition in Table 3. The average change in the number of Nagi functions (out of 9), in the number of ADLs (out of 7), and IADLs (out of 5) one is unable to perform is presented after controlling for the age composition of the samples of people having each of the 13 diseases. There are striking sex differences in the change over ten years in functioning and disability. For men with disease there is almost no change in functioning and disability and the only significant changes indicate increased functioning problems in 1994. For women, the change is quite different. Ability to perform Nagi functions and IADLs clearly improved over the decade. Women with almost all of the conditions experienced significantly less functioning loss and IADL impairment. The decreases in Nagi functioning deficits were largest among women who had heart diseases, strokes, arthritis, and osteoporosis; the decreases in IADL functioning were largest for those with heart disease, stroke, and osteoporosis. In general the greatest improvement was in the Nagi indicators, or the indicators of the most moderate functioning loss. Only for women with diabetes, broken hips, and blindness was there no improvement in these types of functioning.

Any significant change in ADL functioning for both men and women, represented deterioration in functioning over time. For men almost all of the significant functioning changes represented increases in ADL disability in 1994. For women most of the increases were small. Examination of functioning change for those with no disease indicates no change over time in any type of functioning ability among either men or women. Change over the ten-year period in the total sample, including people with any disease and without disease, indicates improvement in Nagi and IADL functioning among women and slight deterioration of ADL functioning among both genders.

\subsection{Co-morbidity}

To this point we have treated diseases individually, not acknowledging the potential for any individual to have multiple diseases or conditions. It is possible that there has been a change over time in the number of diseases people have, in the likelihood of having multiple diseases as well as in the likelihood of having any one disease. We examine the change in the number of reported diseases per person: mortal conditions (range 0 to 5), morbid conditions (range 0 to 4), and 
impairments (range 0 to 4). The regression coefficients representing the increase from 1984 to 1994 from sex-specific equations with age controlled are shown in Table 4. In 1994 both men and women report an average of .3 diseases more than in 1984. For men most of the increase is due to increase in the number of mortal conditions. For women the increase in the number of morbid conditions is greater.

We also use logistic regression to estimate the effect of the time change on the likelihood of having no disease and the likelihood of having extensive comorbidity ( $3+$ diseases). Where there was significant change between the two surveys, we use the results to estimate the probability that a 70 year old man or woman would have no disease or would have three or more diseases in 1984 and 1994 (Table 5). It is clear that in 1994, people are less likely to be without disease. About one third (32\%) of men had no mortal disease in 1994; in 1984, the figure was 41 percent. For women, the percentage having no morbid disease fell from $38 \%$ to $34 \%$. The number of people reporting 3 or more diseases at age 70 increased for both men and women and for both genders the increase was concentrated in mortal diseases.

Some combinations of disease are particularly interesting. The likelihood of persons with heart disease also being cancer survivors was twice as great for men in 1994 as in 1984 . For women the increase was about 50 percent.

Among those who have a mortal disease, there is an increase in the likelihood of also having a morbid condition. Among those with one of the mortal conditions, the likelihood of having at least three comorbid conditions increased by $25 \%$ over the ten years for both men and women.

\section{Summary and Discussion}

The reported prevalence of specific lethal diseases has generally risen in the older noninstitutionalized population in recent years and it appears to have risen more for men than for women. This increase is not surprising given the increased survival from many mortal conditions and the fact that there is little evidence of reductions in disease incidence. Mortality improvement during this period was faster among men than among women. The largest increases in disease prevalence have been in heart disease and cancer, two major causes of old age mortality. Declines in mortality from heart disease have continued from the late 1960s through the present, but decreased mortality from all cancers combined has only recently been a major feature of mortality decline. The increase in reported prevalence of heart disease and cancer most likely results from mortality declines and longer survival for people with these diseases.

There have been some increases in the reported prevalence of non-lethal conditions and impairments, particularly arthritis, osteoporosis and visual conditions. The increase in arthritis 
occurred among both men and women; the prevalence of osteoporosis more than doubled among women perhaps representing increased interest and diagnosis in this condition.

The increased prevalence of diseases has resulted in a decrease in the proportion of the older population with no disease and an increase in the number of diseases comorbid within individuals. This is to be expected where people survive one disease and live long enough to acquire others. If one looks at change in the presence of disease as an indictor of health, the conclusion is that morbidity has been expanding in recent years.

In spite of this increase in the prevalence of disease and comorbidity, functioning and IADL disability improved among older women. This improved functioning among older women appears among women who have most of the diseases investigated and could represent a decrease in the severity of prevalent disease among women. It could result from improvement or expansion of treatment of diseases. Functioning improvement is not reported for women who have no diseases. For older men functioning deteriorates among those with disease. In general, men have more disease in 1994 with similar disability levels to those of 1984; women have more disease at the later date but less disability. As noted above, men experienced both more decline in mortality during this period and a greater increase in disease prevalence and comorbidity. For these reasons men may not have had the same improvement in functioning and disability as women.

While reduction in mortality without evidence of a reduction in disease incidence would lead us to expect the empirical evidence to reflect an increase in prevalence of disease between 1984 and 1994, disease prevalence can clearly be influenced by changes in factors other than the physical condition of the population. Peoples' awareness of disease states can change with improvements in diagnosis. In addition, cohorts who use more health care services are likely to be more knowledgeable about disease states because of their contact with the medical establishment. It is also possible that people have medicalized some conditions that were once regarded as "aging" and not disease. For instance, people may now be more likely than in the past to declare aches and pains to be arthritis and osteoporosis. There has been a small decrease in the percent of the older population institutionalized during this time (from 6.3 to 5.2 percent) [Manton, Stallard, and Corder 1997]. While this small change is not enough to account for the changes observed here, it does increase the proportion of the population with health problems.

The results presented in this paper are actually fairly consistent with the existing literature. Results are quite similar to those for France which are also based on the comparison of two crosssectional surveys in a similar period [Robine, Mormiche, Sermet 1998]. Both studies show some improvement in disability accompanied by increases in disease prevalence. Studies using different data sets, time periods, and sometimes different age groups for the United States have also resulted in generally similar findings on changes in disease prevalence as well as disability and functioning changes. 
Findings for the older U.S. population using annual cross-sectional surveys [Crimmins, Saito, and Reynolds 1997] and two longitudinal surveys [Crimmins, Saito, and Reynolds 1997, Manton, Corder, and Stallard 1993, Manton, Stallard, and Corder 1995, Manton, Stallard, and Corder 1997] have shown a statistically significant but small decrease in the overall level of IADL and ADL disability, primarily due to decreased IADL disability with mixed results on the trends in ADL disability. On the other hand, studies including younger age groups and less severe disability have tended to find improvement in functioning and less disability and some reduction in the prevalence of major diseases including arthritis and heart disease [Crimmins, Saito, and Ingegneri 1997, Crimmins, Reynolds, and Saito 1999, Freedman and Martin 1998, Reynolds, Crimmins, Saito 1998].

Results from the National Long Term Care Survey on changes in disease prevalence are also fairly similar. Manton et al. [Manton, Stallard, and Corder 1995] present the prevalence of a number of diseases in the $65+$ noninstitutionalized population for two dates, 1982 and 1989. Estimates of disease prevalence without controls for disability, produce findings similar to our results. They report increases in prevalence for diabetes, cancer, and arthritis; no change in stroke prevalence, which we find to be true only for women; and a small increase in hypertension, which we find only for men. We differ in our findings for heart disease. Where the study of the $65+$ population finds no change in prevalence, looking at the $70+$ population we find increase. This difference may be due to the age composition of the samples because in earlier studies of the 60-69 year old population we find decreases in cardiovascular conditions in a similar time period [Crimmins, Reynolds, and Saito 1999]. This pattern of improvement in disease prevalence among younger persons and increase among older persons was also found in the French study [Robine, Mormiche, Sermet 1998].

The fact that more older people now report that they have the major mortal diseases of old age means that more people are likely to be undergoing treatment or monitoring of their conditions. More people are likely to be undergoing treatment for multiple conditions. One of the effects of the success at reducing mortality may be a higher prevalence of disease and greater use of medical services.

\section{Acknowledgements}

This research was supported by NIA grant number R01AG11235 and the Nomura Foundation for Social Science.

\section{Notes}

1. Because of initial delays in beginning the survey, the second survey was actually collected in both 1994 and 1995. 


\section{References}

Bloomgarden, Z. T. A review of current trends in diabetes. Diabetes Care, 1994, 17, 7:786-790.

Bonneux, L., Barendregt, J. J., Meeter, K., Bonsel, G. J., van der Maas, P. J. Estimating clinical morbidity due to ischemic heart disease and congestive heart failure: The future rise of heart failure. American Journal of Public Health, 1994, 84, 1: 20-28.

Brown, R. D., Whisnant, J., Sicks, J., OFallon, M., Wiebers, D. Stroke incidence, prevalence, and survival: Secular trends in Rochester, Minnesota, through 1989. Stroke, 1996, 27, 3:373-380.

Crimmins, E., Hayward, M.D., Saito, Y. Changing mortality and morbidity rates and the health status and life expectancy of the older population. Demography, 1994, 31: 159-175.

Crimmins, E., Saito, Y., Ingegneri, D. Trends in disability-free life expectancy in the United States, 1970-1990. Population and Development Review, 1997, 23:555-572.

Crimmins, E., Saito, Y., Reynolds, S. Further evidence on recent trends in the prevalence and incidence of disability among older Americans from two sources: The LSOA and the NHIS. Journal of Gerontology: Social Sciences, 1997, 52B, 1:S59-S71.

Crimmins, E., Reynolds, S, Saito, Y. Trends in health and ability to work among the older workingage population. Journal of Gerontology: Social Sciences, 1999, 54B, 1:S31-S40.

Feinleib, M. Trends in heart disease in the United States. American Journal of the Medical Sciences, 1995, 310, Suppl 1:S8-14.

Freedman, V., Martin, L. Understanding trends in functinal limitations among older Americans. American Journal of Public Health, 1998, 88:1457-1462.

Hann, M. N., Selby, J., Rice, D., Quesenberry, C., Schofield, K., Liu, J., Fireman, B. Trends in cardiovascular disease incidence and survival in the elderly. Annals of Epidemiology, 1996, $6,4: 348-356$.

Liebson, C.L., O’Brien, P.C., Atkinson, E., Palumbo, P.J., Melton, L.J. Relative contributions of incidence and survival to increasing prevalence of adult-onset diabetes mellitus: a populationbased study. American Journal of Epidemiology, 1997, 146:12-22. 
Manton, K.G., Corder, L., Stallard, E. Estimates of change in chronic disability and institutional incidence and prevalence rates in the U.S. elderly population from the 1982, 1984, and 1989 National Long Term Care Survey. Journal of Gerontology: Social Sciences, 1993, 48:S153S166.

Manton, K.G., Stallard, E., Corder, L. Changes in morbidity and chronic disability in the U.S. elderly population: Evidence from the 1982, 1984, and 1989 NLTCS. Journal of Gerontology: Social Sciences, 1995, 50B, 4:S194-S204.

Manton, K.G., Stallard, E., Corder, L. Chronic disability trends in elderly United States' populations: 1982-1994. Proceedings of the National Academy of Sciences, USA: Medical Sciences, 1997, 94: 2593-2598.

Reynolds, S., Crimmins, E., Saito, Y. Cohort differences in disability and disease presence. The Gerontologist, 1998, 38: 578-590.

Robine, J.-M., Mormiche, P., Sermet, C. Examination of the causes and mechanisms of the increase in disability-free life expectancy. Journal of Aging and Health, 1998, 10, 2:171-191.

Shahar, E., McGovern, P., Pankow, J., Doliszny, K., Smith, M., Blackburn, H., Luepker, R. Stroke rates during the 1980s: The Minnesota Stroke Survey. Stroke, 1997, 28, 2:275-279.

Verbrugge, L.M., Jette, A.M. The disablement process. Social Science and Medicine, 1994, 38: 1-14. 
Table 1:

Comparison of Questions asked in 1984 and 1994 in SOAI and SOAII

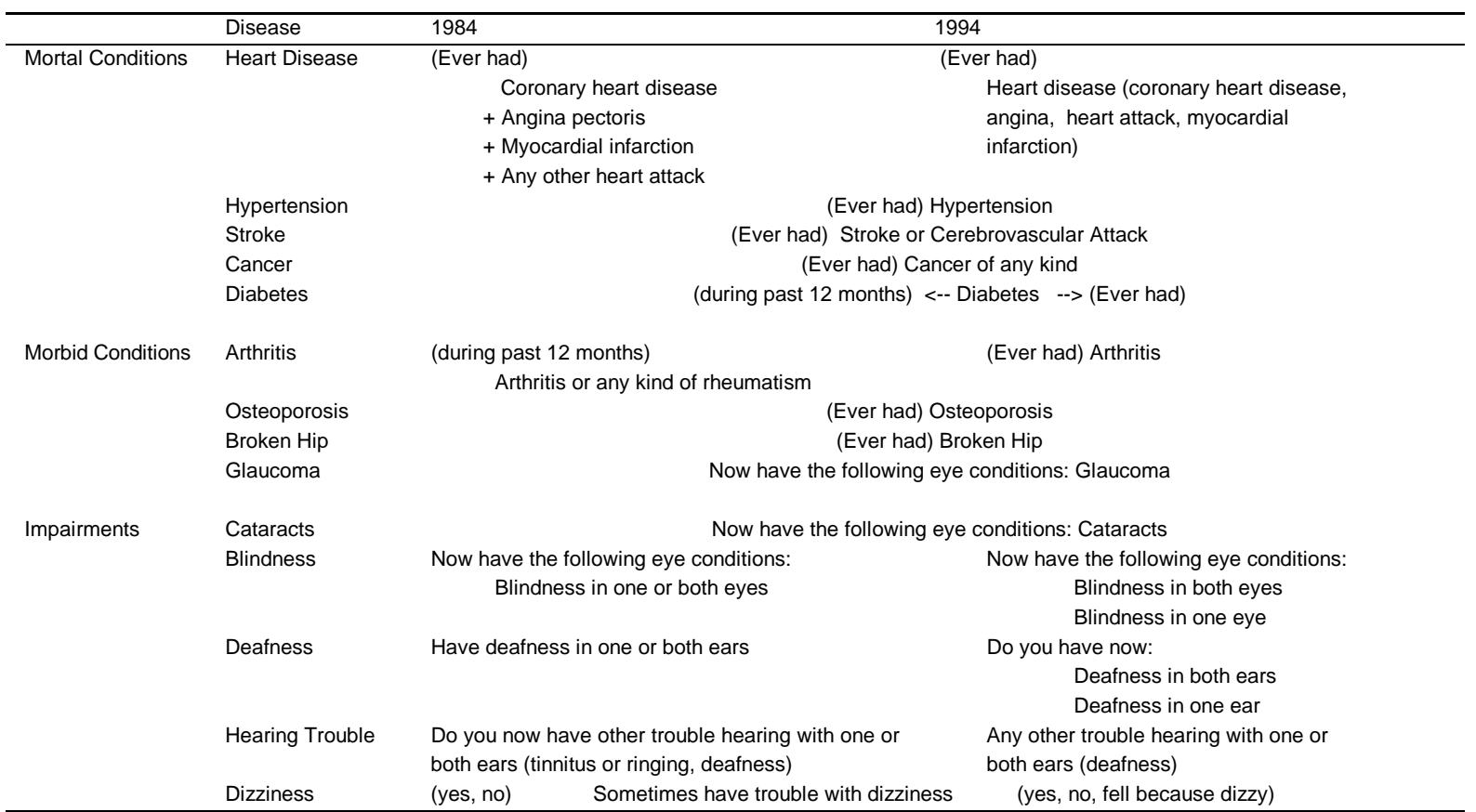

1984: Yes, No, DK or refused; 1994: Yes, No, not ascertained, DK or refused 
Table 2:

Estimated Probability of Having Specified Disease at Age 70: 1984 and 1994 U.S.

Noninstitutionalized Population

\begin{tabular}{|c|c|c|c|c|c|}
\hline & & \multicolumn{2}{|c|}{ Males } & \multicolumn{2}{|c|}{ Females } \\
\hline & & 1984 & 1994 & 1984 & 1994 \\
\hline \multirow[t]{5}{*}{ Mortal Diseases } & Heart Disease & .19 & .25 & .12 & .16 \\
\hline & Hypertension & .40 & .43 & .49 & .47 \\
\hline & Stroke & .07 & .09 & --- & --- \\
\hline & Cancer & .12 & .21 & .11 & .16 \\
\hline & Diabetes & .11 & .14 & .12 & .13 \\
\hline \multirow[t]{4}{*}{ Morbid Conditions } & Arthritis & .44 & .49 & .59 & .62 \\
\hline & Osteoporosis & .01 & .01 & .05 & .12 \\
\hline & Broken Hip & --- & --- & --- & --- \\
\hline & Glaucoma & .04 & .06 & .05 & .08 \\
\hline \multirow[t]{4}{*}{ Impairments } & Cataracts & .13 & .16 & .21 & .24 \\
\hline & Blindness & --- & --- & .03 & .03 \\
\hline & Hearing Trouble* & --- & --- & --- & --- \\
\hline & Dizziness & --- & -- & --- & --- \\
\hline
\end{tabular}

--- No Significant Change at .05 level

* Hearing trouble includes deafness in one or both ears and other trouble hearing with one or both ears.

Source: SOAI,SOAll. Estimates computed from logistic regressions of age, and year of survey on presence of disease. 
Table 3:

Estimated Changes Between 1984 and 1994 for U.S. Noninstitutionalized Population, 70+, in Number of Nagi Functions, ADL Tasks, and IADL Tasks Unable to Perform Among Those with Specific Disease, Among Those with No Disease, and Total Sample ${ }^{\mathrm{a}}$

\begin{tabular}{|c|c|c|c|c|c|c|}
\hline \multirow[t]{2}{*}{$\begin{array}{l}\text { People with } \\
\text { Specified Disease }\end{array}$} & \multicolumn{3}{|c|}{ Males } & \multicolumn{3}{|c|}{ Females } \\
\hline & Nagi & IADL & $A D L$ & Nagi & IADL & $A D L$ \\
\hline Heart disease & ns & ns & ns & -0.353 & -0.215 & ns \\
\hline Hypertension & ns & ns & ns & -0.184 & ns & 0.090 \\
\hline Stroke & ns & ns & 0.289 & -0.656 & -0.418 & ns \\
\hline Cancer & ns & ns & ns & -0.193 & -0.156 & ns \\
\hline Diabetes & 0.285 & 0.171 & ns & ns & ns & ns \\
\hline Arthritis & ns & ns & 0.076 & -0.220 & -0.061 & 0.216 \\
\hline Osteoporosis & ns & ns & ns & -0.497 & -0.231 & 0.064 \\
\hline Broken hip & ns & ns & ns & ns & ns & ns \\
\hline Cataracts & ns & ns & 0.109 & -0.134 & -0.080 & ns \\
\hline Glaucoma & ns & ns & ns & ns & -0.167 & ns \\
\hline Blindness & ns & ns & ns & ns & ns & ns \\
\hline Trouble hearing & ns & ns & ns & -0.213 & -0.087 & 0.094 \\
\hline Dizziness & ns & ns & 0.121 & -0.298 & -0.129 & ns \\
\hline $\begin{array}{l}\text { People with no } \\
\text { disease }\end{array}$ & ns & ns & ns & ns & ns & ns \\
\hline Total Sample & ns & ns & 0.067 & -0.136 & -0.040 & 0.057 \\
\hline
\end{tabular}

ns: $\quad$ not significant at the .05 level. Source: SOAI, SOAll.

a Model includes age control and year dummy (1984 coded as 0 and 1994 coded as 1 ). 
Demographic Research - Volume 3, Article 9

\section{Table 4:}

Estimated Change Between 1984 and 1994 in Average Number of Diseases and Impairments, U.S. Noninstitutionalized Population, 70+

\begin{tabular}{lcc}
\hline & Males & Females \\
\hline \# Mortal & 0.238 & 0.093 \\
\# Morbid & 0.076 & 0.141 \\
\# Impairment & $\mathrm{ns}$ & $\mathrm{ns}$ \\
\# Total Diseases & 0.340 & 0.265 \\
\hline
\end{tabular}

ns: $\quad$ not significant at .05 level.

Source: SOAI, SOAll. 
Demographic Research - Volume 3, Article 9

\section{Table 5:}

Estimated Probability of Having No Disease or 3+ Conditions at Age 70: 1984 and 1994, U.S. Noninstitutionalized Population

\begin{tabular}{|c|c|c|c|c|}
\hline \multirow[b]{2}{*}{ Number of Diseases } & \multicolumn{2}{|c|}{ Males } & \multicolumn{2}{|c|}{ Females } \\
\hline & 1984 & 1994 & 1984 & 1994 \\
\hline 0 Mortal & 0.41 & 0.32 & 0.39 & 0.38 \\
\hline 0 Morbid & 0.54 & 0.49 & 0.38 & 0.34 \\
\hline 0 Impairment & -- & -- & -- & -- \\
\hline 0 Total & 0.17 & 0.14 & -- & -- \\
\hline 3+ Mortal & 0.06 & 0.10 & 0.05 & 0.07 \\
\hline 3+ Morbid & -- & -- & 0.01 & 0.02 \\
\hline 3+ Impairments & -- & -- & -- & -- \\
\hline $3+$ Total & 0.34 & 0.41 & 0.39 & 0.43 \\
\hline
\end{tabular}

--- $\quad$ No Significant Change at .05 level.

Source: SOAI,SOAll. 


\section{Figure 1}

Significant* Odds Ratios Indicating Time Change in Mortal Conditions:

U.S. Noninstitutionalized Population, 70+

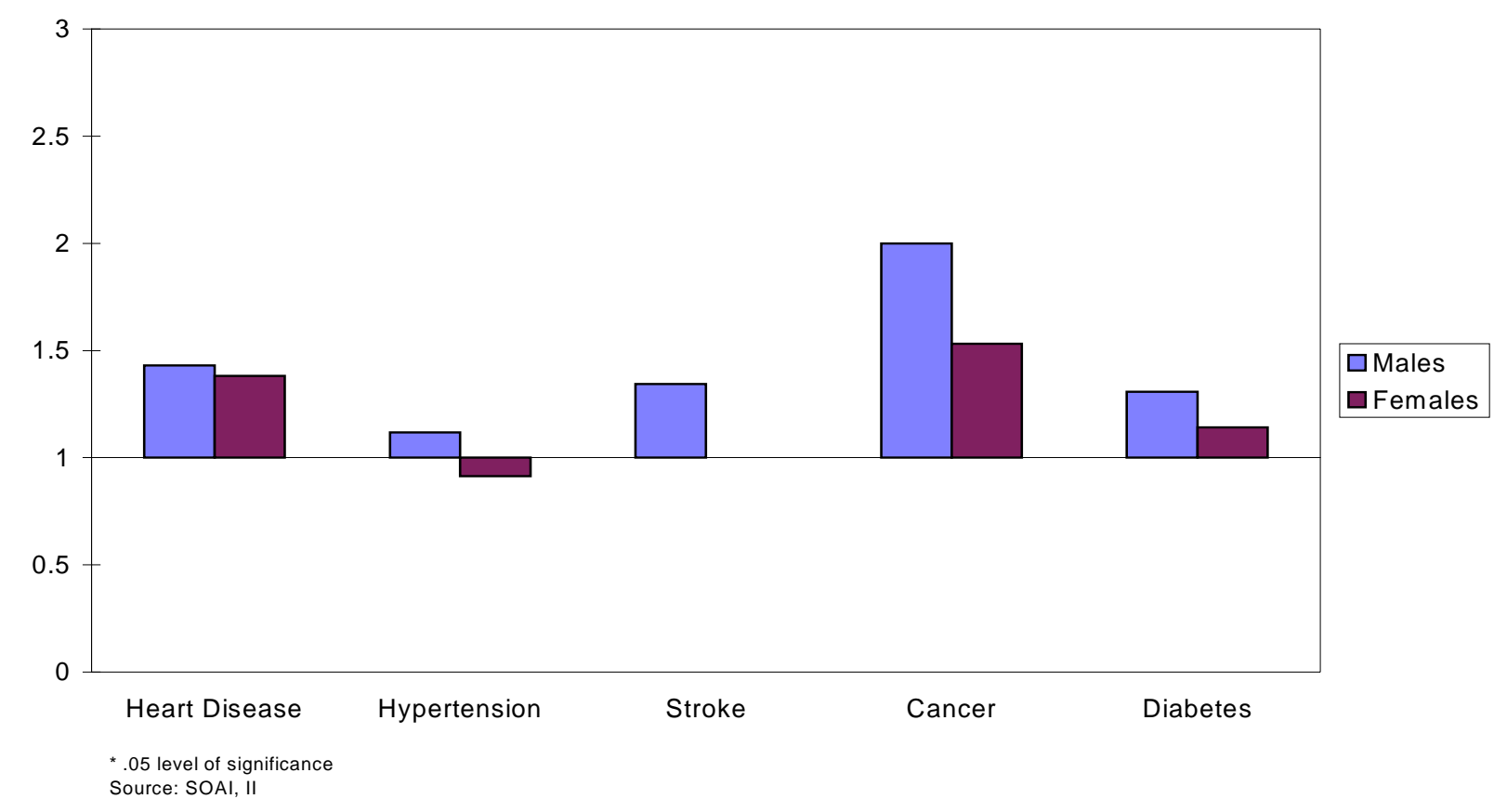




\section{Figure 2}

Significant* Odds Ratios Indicating Time Change in Non-mortal Conditions:

U.S. Noninstitutionalized Population, 70+

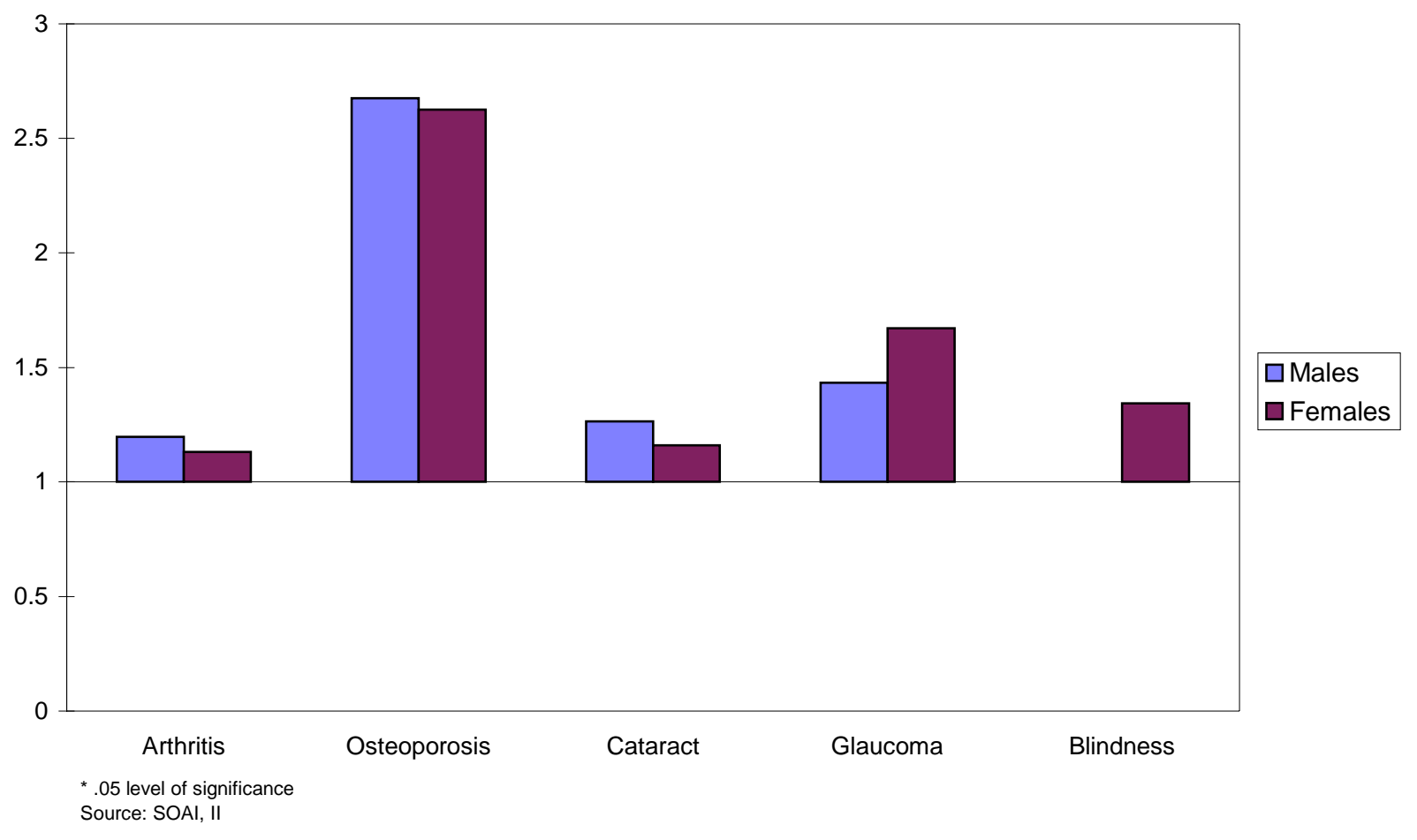

